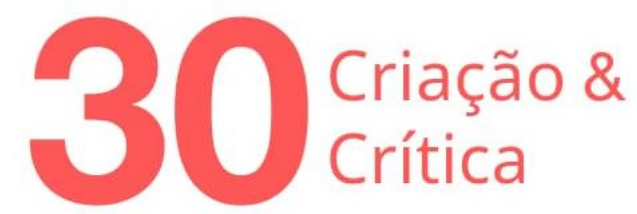

\section{UMA RETÓRICA DO PODER}

José Antônio Orlando ${ }^{1}$

Vera Casa Nova ${ }^{2}$

RESUMO: O discurso de poder, questão sempre relevante em Roland Barthes, remonta a seus primeiros exercícios de crítica, traduzidos nos artigos fragmentados de Mitologias, e pode ser visto como prisma de toda a sua obra, com destaque para as reflexões apresentadas em Aula, que permanece como um dos textos mais intensos e mais radicais do autor. O objetivo deste artigo é analisar a questão a partir de reflexões e questionamentos do próprio Barthes e de autores que também abordam temas correlatos, como Michel Foucault e Susan Sontag, especialmente na interface com o biopoder e a biopolítica, conceitos que alcançam grande atualidade e relevância no cenário político brasileiro e no contexto da pandemia de covid-19. PALAVRAS-CHAVE: discurso de poder, biopoder, biopolítica, pandemia, utopia.

\section{A RHETORIC OF POWER}

ABSTRACT: The discourse of power, an always relevant issue in Roland Barthes, goes back to his first critical exercises, translated in the fragmented articles of Mythologies, and can be seen as a prism of his entire work, with emphasis on the reflections presented in Aula, which remains one of the author's most intense and radical texts. The aim of this article is to analyze the issue from reflections and questions by Barthes himself and authors who also address similar themes, such as Michel Foucault and Susan Sontag, especially in the interface with biopower and biopolitics, concepts that have great relevance to the Brazilian political scenario and in the context of the covid-19 pandemic.

KEYWORDS: power speech, biopower, biopolitics, pandemic, utopia.

O que pensamos aqui é uma questão sempre relevante em Roland Barthes: o discurso de poder. Questão que poderá ser desdobrada pela história de cada sociedade, em tempos de excessos e devires e repetições. Diz-nos Barthes:

Chamo discurso de poder todo discurso que engendra o erro e, por conseguinte, a culpabilidade daquele que o recebe. Alguns esperam de nós, intelectuais, que nos agitemos a todo momento contra o poder. Mas nossa verdadeira guerra está alhures: ela é contra os poderes, e não é um combate fácil: pois, plural no espaço social, o poder é, simetricamente, perpétuo no tempo histórico: expulso, extenuado aqui, ele reaparece ali; nunca perece; façam uma revolução para destruí-lo, ele vai imediatamente reviver, re-germinar no novo estado de coisas (BARTHES, 1978, p. 11-12).

1 Doutorando em Estudos Literários, na linha de pesquisa Literatura, História e Memória Cultural, pela Universidade Federal de Minas Gerais (UFMG). Bolsista Capes. E-mail: semioticas@hotmail.com

2 Doutora em Ciência da Semiologia pela Universidade Federal do Rio de Janeiro (UFRJ) e pósdoutora pela École des Hautes Études en Sciences Sociales (EHESS). Professora da Faculdade de Letras da UFMG. E-mail: veracasanova1@gmail.com 


\section{$300_{\substack{\text { Criticáa o } \\ \text { crica }}}$}

Em 1977, em sua magistral Aula Inaugural da cadeira de Semiologia Literária no Collège de France, depois publicada em um livro que, apesar de sua pequena extensão, permanece como um dos textos mais intensos e mais radicais do autor, Barthes alerta que a "inocência" moderna fala do poder como se ele fosse apenas um, ignorando que ele está em toda parte, por todos os lados, em grupos de opressão ou de pressão, plural como os demônios ("Meu nome é Legião"). O poder segue emboscado em detalhes, onde não o ouvíamos de início, em todo e qualquer discurso - mesmo quando este parte de um lugar fora do poder, nas modas, nas opiniões correntes, nos espetáculos, no esporte, nas opiniões familiares. Passam por muitos caminhos a atualidade de Barthes e seu alerta sobre o discurso de poder. Passam pelos afetos e pelas paixões, pelo corpo, pela língua que obriga a dizer, pela leitura das mitologias contemporâneas que omitem o mais importante, pela interpretação do verbal ao não verbal, pelo incerto, pelo neutro, pelo falso, pelos efeitos do real, pelos cruzamentos constantes do real com o ficcional no discurso das mídias e pelas imagens em seus sentidos óbvios e obtusos.

Logo depois de indicar a linguagem como uma legislação e a língua como seu código, Barthes insere, em sua Aula Inaugural, uma questão que foi deixada de lado por algum tempo e que, também a partir da década de 1970, seria retomada por outros intelectuais, sobretudo por Michel Foucault: o poder e as condutas do biopoder, os mecanismos de regulação da vida e de controle dos corpos. Em Barthes, localizamos essa analogia permanente entre linguagem e política, talvez porque as relações humanas sempre estiveram baseadas em relações de poder: ele assinala e demonstra que a linguagem e sua expressão obrigatória, a língua, são e sempre foram instrumentos de poder e coerção social. Elas fortalecem e disseminam ideologias, enquanto a literatura, para além da arte e da expressão, para além do que realça de redenção e de libertação, também é uma forma de exercício de poder.

A língua é fascista - como aponta a citação tantas vezes repetida em contextos diversos - mas Barthes faz a ressalva de que a literatura, e a arte, por extensão, conseguem trapacear com a língua, trapacear a língua: conseguem metamorfosear o sentido em algo libertário. $E$, pelo logro magnífico da liberdade, possibilitam a tomada de posição contra as convenções e em resistência à opressão:

Poderíamos imaginar uma história da literatura, ou, melhor, das produções de linguagem, que seria a história dos expedientes verbais, muitas vezes louquíssimos, que os homens usaram para reduzir, aprisionar, negar, ou pelo contrário assumir o que é sempre um delírio, isto é, a inadequação fundamental da linguagem. Eu dizia há pouco, a respeito do saber, que a literatura é categoricamente realista, na medida em que ela sempre tem o real por objeto de desejo; e direi agora, sem me contradizer, porque emprego a palavra em sua acepção familiar, que ela é também obstinadamente: irrealista; ela acredita sensato o desejo do impossível (BARTHES, 1978, p. 23). 


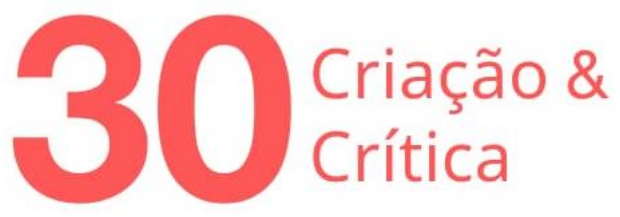

O que permanece, em Barthes, não são as grandes verdades subjetivas, mas sim, principalmente, os questionamentos. Nas referências, ele encontra Voltaire, para quem um homem deve ser julgado mais pelas suas perguntas do que pelas suas respostas. São os questionamentos das análises decifrando os enigmas do real nos textos de Barthes que levam ao saber com sabor e movem os deslocamentos das palavras, da "nouvelle cuisine" à "nouvelle critique", da provocação iconoclasta à sedução que revela e acrescenta alternativas. Para significar mais e melhor em sua linguagem, em sua força de representação, para que possa gerar outros contornos, outras vozes, outros sentidos, outras possibilidades de contradição e subversão política, a literatura, como Barthes destaca, apresenta o convite de sua função utópica: ela acredita sensato o desejo utópico do impossível.

Com a atualidade da lição de Barthes, vemos que a língua não somente é proferida a serviço de um poder. Ela também está presente como principal mediadora dos poderes e como desempenho de todas as linguagens, porque toda língua é uma classificação e toda classificação é opressiva.

Assim, por sua própria estrutura, a língua implica uma relação fatal de alienação. Falar, e com maior razão discorrer, não é comunicar, como se repete com demasiada frequência, é sujeitar: toda língua é uma reição generalizada (...). Mas a língua, como desempenho de toda linguagem, não é nem reacionária, nem progressista; ela é simplesmente: fascista; pois o fascismo não é impedir de dizer, é obrigar a dizer (BARTHES, 1978, p. 13-14).

É preciso lembrar que estamos dentro do território dos signos e, para Barthes, o signo da servidão e o signo do poder se confundem inelutavelmente: assim que é proferida, Barthes destaca, a língua entra a serviço de um poder. Ao lembrar tal relação, em seus meandros de intermitência e interdependência, encontramos uma lição fundamental à qual Barthes retornou muitas vezes: Étienne de La Boétie em seu Discurso da servidão voluntária, um autêntico hino à liberdade escrito no século XVI. Assim como seu contemporâneo e amigo pessoal Michel de Montaigne, Étienne de La Boétie afirma a liberdade e a igualdade de todos os homens na dimensão política, evidenciando, pela primeira vez na história, a força da opinião pública. Considerando que todos têm seu direito natural à liberdade, ao mesmo tempo que o poder do tirano aumenta, progressivamente, à medida que seus súditos aceitam sua condição subserviente, La Boétie constata os infortúnios que o mau encontro de um tirano com o poder sempre pode provocar e questiona:

Ver infinitas pessoas servindo em vez de obedecer, sendo tiranizadas em vez de governadas; sendo desprovidas de bens e parentes, mulheres e crianças, até mesmo de uma vida própria! Sofrendo as pilhagens, as obscenidades, as crueldades, não de uma armada, não de um exército bárbaro do qual devam, antes de tudo, defender seu sangue e sua vida, mas sim de um único indivíduo; não de um 


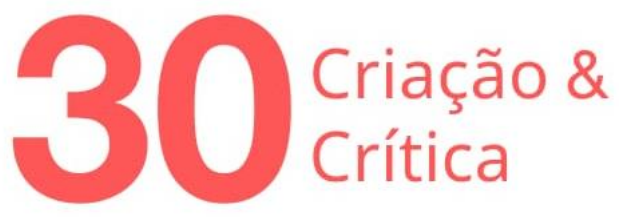

Hércules nem de um Sansão, mas de um reles homenzinho (LA BOÉTIE, 2017, p. 36).

Tal como Étienne de La Boétie destaca que é possível resistir à opressão e que é pela tomada de consciência que os súditos destituem o tirano, porque a tirania se destrói sozinha quando os indivíduos se recusam a consentir com sua própria escravidão, Barthes, em seus questionamentos sobre o discurso de poder, vai ressaltar possibilidades de redenção sobre o lugar da liberdade para enfrentar as armadilhas e os desafios da linguagem, suas formas retóricas ostensivas ou disfarçadas de controle e submissão. Analisando e interpretando a política da ideologia burguesa de sua época, Barthes revela, a partir de séries de exemplos correntes no senso comum, como certas figuras conseguem construir, em dispositivos de dominação pelas práticas discursivas, uma visão de mundo considerada natural e até mesmo inevitável. A servidão voluntária é o grande enigma da vida política, como aponta La Boétie, mas Barthes, desde a década de 1950, já estabelecia um contraponto:

É a história que transforma o real em discurso, é ela e só ela que comanda a vida e a morte da linguagem mítica. Longínqua ou não, a mitologia só pode ter um fundamento histórico, visto que o mito é uma fala escolhida pela história: não poderia de modo algum surgir da "natureza" das coisas (BARTHES, 1972, p. 132).

A tese sobre o poder repressivo do discurso, que domina a Aula Inaugural ("a língua é simplesmente fascista"), também pode ser vista como prisma de toda a obra anterior de Barthes, uma vez que remonta a seus primeiros exercícios de crítica traduzidos nos artigos fragmentados de Mitologias e no ensaio mais extenso que conclui a coletânea, nomeado como "O mito, hoje". Desde então, há uma percepção consensual que Barthes apresentou como categoria de análise: o mito é uma fala, essa fala é uma mensagem, um modo de significação. A interpretação de Barthes torna-se uma interface para a contemporaneidade do mito, porque a partir de suas atribuições de sentido tudo passou a servir de suporte à fala mítica: representações diversas como as palavras, o discurso escrito, a fotografia, o cinema, a arte, a reportagem, o esporte, os espetáculos, a publicidade e toda síntese significativa que sob determinada circunstância venha estabelecer uma forma de linguagem, seja ela ou verbal ou sonora ou visual.

No caleidoscópio dos breves artigos publicados na imprensa a partir de 1954 e depois reunidos no livro de 1957, Barthes demonstra que tipos específicos de poder operam na sociedade burguesa: os rituais da "doxa" desmascarada, como farsa e repetição de convenções, nos convidam a reflexões e investigações sobre detalhes na aparência menores e insignificantes, mas que funcionam como ponto de partida para grandes descobertas. São recortes, cada um a seu modo, tomados como exemplo lapidar: o trabalho monumental de deuses, de heróis milenares e de sagas épicas sobrevive em mitos e mitologias de anúncios publicitários, de reportagens de jornais e revistas, de narrativas do cinema e da TV. Essa sobrevivência de imagens 


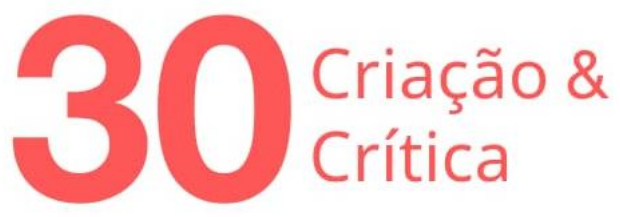

nos mais diversos aparatos discursivos e midiáticos também é reconsiderada em nossa atualidade por Georges Didi-Huberman (2013), a partir da obra do historiador Aby Warburg, quando a memória consegue trazer à tona o pathos da cultura. A história da arte e a história das imagens nãovivem apenasao ritmo manifesto dos renascimentos ou da obsolescência dos esquecimentos - elas também vivem ao ritmo mais latente de certas sobrevivências, como alertava Warburg no começo do século passado.

No cenário das mitologias contemporâneas, na cena dos signos, nos embates e nas analogias entre linguagem e política, o discurso de poder por vezes se impõe pela força bruta, por vezes pelo convencimento, por vezes por insinuações. Barthes reconhece:

A semiologia, no que me concerne, partiu de um movimento propriamente passional: pareceu-me (por volta de 1954) que uma ciência dos signos podia ativar a crítica social, e que Sartre, Brecht e Saussure podiam juntar-se nesse projeto; tratava-se, em suma, de compreender (ou de descrever) como uma sociedade produz estereótipos, isto é, cúmulos de artifício, que ela consome em seguida como sentidos inatos; isto é, cúmulos de natureza. A semiologia (minha semiologia, pelo menos) nasceu de uma intolerância para com essa mistura de má-fé e de boa consciência que caracteriza a moralidade geral, e que Brecht chamou, atacando-a, de Grande Uso. A língua trabalhada pelo poder: tal foi o objeto dessa primeira semiologia (BARTHES, 1978, p. 33).

As investigações críticas do legado de Barthes ressaltam, nas relações entre língua e linguagem, entre cultura e ideologia, entre as ações e suas funções, que as convenções estruturais informam tanto como a criatividade em processos de mudança e de reação contínua. A função utópica de outros modos de pensar, aquele constante trapacear com a língua, "esplendor de uma revolução permanentemente da linguagem", que ele chamará, simplesmente, de "literatura" (BARTHES, 1978, p. 16), em sua força de representação, tem valor porque interroga o mundo e não porque o explica. Os questionamentos e a perspicácia crítica orientam a trajetória, seus rastros coordenados, na cartografia de um escritor que seguiu adaptando e refutando significados e sentidos da estabilidade, da constância, dos cânones e dos totens consagrados às referências. Como nos diz Leyla Perrone-Moisés: "Ele era um sujeito muito indisciplinado para se acomodar numa ciência canônica, e demasiadamente desconfiado para acreditar que os signos, tão numerosos e móveis, pudessem ser classificados rigorosamente em esquemas científicos" (PERRONE-MOISÉS, 1983, p. 57).

As questões que Barthes destaca envolvendo linguagem e política, língua e ideologia, também encontram reflexos importantes no pensamento de seu amigo e interlocutor Michel Foucault, um historiador que também percebia na arte tanto as formas para o homem sublimar suas angústias, como as alegorias mais importantes para localizar pontos de inflexão sobre questões sociais expressas por todo tipo de discurso. Nas reflexões de Foucault, o poder se desdobra nesta interface, o problema 


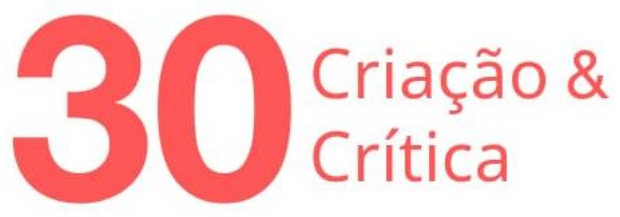

do biopoder, que ele identifica em dois estudos datados de 1976, o curso Em defesa da sociedade (1999) e o primeiro volume de História da sexualidade: a vontade de saber (2010). Foucault investiga e enumera questões do biopoder na trajetória das sociedades ocidentais, nas quais a configuração de uma biopolítica das populações fica estabelecida com um determinado deslocamento do poder disciplinar do soberano. O poder sobre as ações individuais no tecido social se move, gradativamente, para o poder sobre as ações impessoais, orientado para regulação e controle dos mais diversos aspectos e processos relacionados à vida das pessoas. Esse controle sobre a vida individual e sobre os corpos ele denomina biopoder, considerando não somente o plano econômico, o corpo envolvido como capacidade de produção, mas também o plano biológico, envolvido nas questões de sexualidade, de reprodução, de saúde, de longevidade, de mortalidade.

A atualidade das questões relacionadas ao conceito de biopoder reluz em nossos tempos sombrios da pandemia provocada pelo coronavírus e seus recordes macabros de números de mortos, destacando da forma mais brutal nossa realidade biológica fundamental. Nos estudos de Foucault, as epidemias, as pestes, a morte tornada iminente para todos, são contrapontos que atormentavam os poderes políticos desde a Idade Média e que avançam até nossos dias. A questão imperativa que se mantém com a chegada dos mecanismos da revolução industrial, em nossos tempos sombrios alcança uma ressonância quase profética, confirmada pela subtração das forças produtivas, pelo isolamento social forçado e pelo tempo de trabalho não realizado - a morte permanente que assombra e se introduz sorrateiramente na vida, que a diminui e enfraquece. Palavras de Foucault:

Fora do mundo ocidental, a fome existe numa escala maior do que nunca; e os riscos biológicos sofridos pela espécie são talvez maiores e, em todo caso, mais graves do que antes do nascimento da microbiologia. Mas o que se poderia chamar de 'limiar de modernidade biológica' de uma sociedade se situa no momento em que a espécie entra como algo em jogo em suas próprias estratégias políticas. $\mathrm{O}$ homem durante milênios permaneceu o que era para Aristóteles: um animal vivo e, além disso, capaz de existência política; o homem moderno é um animal em cuja política sua vida de ser vivo está em questão (FOUCAULT, 2010, p. 156).

Foucault retornaria ao problema do biopoder e da biopolítica em diversos estudos e conferências, analisando suas transformações nos últimos séculos e traçando coordenadas sobre suas configurações, nas sociedades ocidentais, pelo viés do exercício do poder que toma a vida como objeto de sua regulação, de forma autoritária e sem legitimidade. Tais transformações, que não raro consistem na inclusão de processos biológicos nas operações do poder, têm por base que, historicamente, o soberano é aquele cujo poder fundamentalmente reside no direito sobre a vida e a morte de homens e mulheres que estejam no território demarcado sob seu comando - sendo a soberania aquela entidade que não conhece superior na 


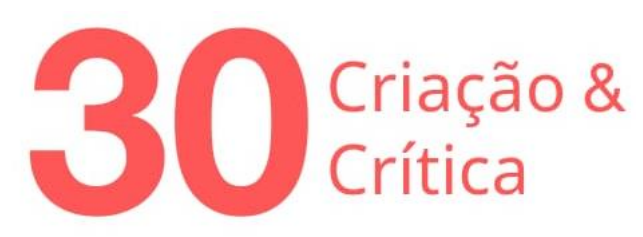

ordem externa nem igual na ordem interna, um poder não ilimitado, embora absoluto, conforme o conceito clássico definido no século XVI por Jean Bodin, para quem "a soberania é o poder absoluto e perpétuo de um Estado-Nação" (BODIN, 2011, p. 195).

A fim de assegurar a defesa incondicional de si próprio ou de seu território, era permitido ao soberano valer-se de seus súditos, mesmo que os conduzindo ao aniquilamento, estando igualmente ao seu alcance aplicar castigos a infratores, punindo-os com a prisão ou com a execução. Foucault adverte que massacres e extermínios também passaram a ser dispositivos complementares a determinadas estruturas de poder nos últimos séculos, mas se antes o expediente de guerras sangrentas era iniciado a fim de proteger o soberano, na era da vigência do biopoder há o argumento genocida de que a morte de uns vai assegurar a existência de todos. Tal forma de equivaler vida e morte será encontrada na base do biopoder exercido por estruturas administrativas e de governo - chegando a extremos de pressupor a existência de um vínculo intrínseco entre prosperidade e extermínio, sendo esse extermínio a derradeira aniquilação física e também a morte política, a expulsão, a rejeição etc. (FOUCAULT, 1999, p. 306).

No Brasil, nesses tempos sombrios em que coincidem a pandemia de covid-19 e um governo federal de orientação equivocada e fascista, em muitos aspectos, assistimos a uma triste atualização dos conceitos de biopoder e biopolítica. Com os números de óbitos provocados pelo coronavírus se multiplicando e batendo recordes, sem nenhuma reação e nenhum plano de ação para contenção da pandemia pelo governo do presidente Jair Bolsonaro, não parece nenhum exagero nomear a situação como genocídio - como vêm destacando diversos analistas políticos e cientistas no Brasil e no exterior, em publicações e reportagens feitas por veículos de imprensa conceituados como The Guardian, The Washington Post, The New York Times, Le Monde, El País, BBC, Deutsche Welle e Der Spiegel, entre outros. Em 14 de dezembro de 2020, uma reportagem em destaque na primeira página do The New York Times, com o título "Brincando com vidas" ("Playing with lives"), alertava que o plano brasileiro de vacinação contra covid-19 estava mergulhado no caos. Segundo a reportagem, enquanto outros países se apressavam em seus preparativos para vacinar e imunizar seus cidadãos, "lutas políticas internas, planejamento aleatório e um crescente movimento antivacinas transformaram o Brasil em um conto de advertência na época do coronavírus" (PLAYING... 2020).

No The Guardian, a reportagem principal em 24 de janeiro de 2021 descrevia, a partir do título, que o desastre da covid-19 no Brasil configurava "um massacre completo, um filme de terror" e anunciava que "grande parte da raiva é dirigida ao governo do presidente de extrema direita do Brasil, Jair Bolsonaro, que banalizou a covid-19 mesmo quando o número de mortos em seu país disparou para o segundo maior da Terra" (A COMPLETE..., 2021). No mesmo jornal britânico, o principal editorial em 5 de abril de 2021 teve como título "A visão do The Guardian sobre Jair Bolsonaro: um perigo para o Brasil e para o mundo", descrevendo que o presidente brasileiro "não apenas usou uma lei de segurança nacional da época da ditadura para perseguir os críticos e supervisionou o maior aumento do desmatamento da Amazônia 


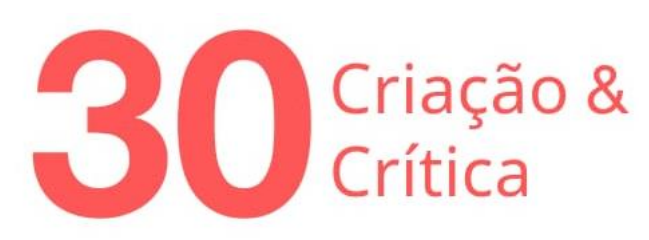

em 12 anos, mas também permitiu que o coronavírus se alastrasse sem controle, atacando as restrições de movimento, máscaras e vacinas" (EDITORIAL..., 2021). No The Washington Post, um editorial de 2 de abril de 2021 também destacava a "impressionante incompetência" (OPINION..., 2021) do governo Bolsonaro, que não tomou medidas para combater a pandemia de covid-19 e também representava uma ameaça à democracia brasileira.

O editorial do The Washington Post começava alertando que "o Brasil está vivendo um dos piores picos de infecções por covid-19 que o mundo já viu", denunciava que as medidas de bloqueio necessárias para retardar novas infecções continuavam praticamente inexistentes no território brasileiro e que "em vez de lutar contra o coronavírus, Bolsonaro parece estar preparando as bases para outro desastre: um golpe político contra os legisladores e eleitores que poderiam removê-lo do cargo". (OPINION..., 2021). Na BBC de Londres, uma reportagem publicada em destaque em 5 de março de 2021 denunciava os recordes sucessivos de mortos e de contaminados no Brasil, que deixavam em crise o sistema de saúde, enquanto o presidente da República fazia chacotas, minimizava a doença e atacava com frequência as medidas que cidades e estados decretavam para tentar conter a pandemia. O título da reportagem anunciava: "Covid: Bolsonaro diz aos brasileiros para 'pararem de choramingar' enquanto as mortes aumentam" (COVID..., 2021).

Também na $B B C$, no noticiário em português da agência $B B C$ News Brasil, uma reportagem publicada em 4 de março de 2021 relatava que, diante dos recordes diários de mortes pela covid, o presidente brasileiro declarou que o choro pelas vítimas era "frescura" e "mimimi", classificando como "idiotas" aqueles que cobravam na imprensa e nas redes sociais da internet a compra de vacinas pelo governo. A reportagem denunciava que o presidente mentiu ao declarar que "o Brasil é um dos países que mais vacinam no mundo" e concluía listando que "desde o início da pandemia, Bolsonaro já se referiu à covid-19 como uma 'gripezinha', perguntou 'e daí?' ao ser confrontado com o número recorde de mortes no país e afirmou que 'todos vamos morrer um dia'" (EM PIOR..., 2021).

Na agência de notícias alemã Deutsche Welle, a reportagem em destaque em 15 de abril de 2021 teve como título "Estudo atribui fracasso do Brasil na pandemia ao governo federal", completando no subtítulo que uma pesquisa publicada na revista científica Science afirmava que "combinação perigosa de inação e irregularidades por parte da gestão Bolsonaro foi principal culpada pela rápida disseminação da covid-19 e pelo cenário de caos no país" (ESTUDO..., 2021). Também no espanhol El País ganhou destaque a questão do descontrole da gestão de Bolsonaro e sua promoção de remédios ineficazes, apontados como causadores de mortes evitáveis, de acordo com relatórios técnicos produzidos pela revista Science e pela organização Médicos Sem Fronteiras, que têm equipes trabalhando na crise sanitária no Brasil e em outros países. Em 15 de abril de 2021, a principal manchete do El País destacava: "Inação e desinformação do governo Bolsonaro agravam a pandemia no Brasil” (INAÇÃO..., 2021).

As críticas e as denúncias contra a incompetência, a inação, a desinformação e as irregularidades do governo Bolsonaro na ausência de enfrentamento contra a 


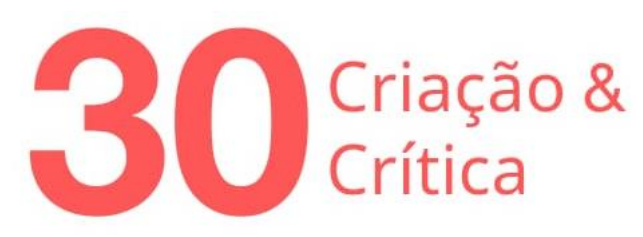

pandemia, com seus resultados desastrosos, também surgem no jornalismo brasileiro, mas na maioria das vezes com o posicionamento isolado de analistas políticos ou cientistas, e não como posicionamento explícito em editoriais dos veículos de imprensa. Um dos casos recentes de crítica e denúncia sobre a situação desesperadora provocada pela covid-19, que não encontra nenhuma reação ou atitude do governo federal para conter a tragédia do crescente número de mortos e de contaminados pela pandemia, veio do historiador e professor de Literatura Comparada da Universidade do Estado do Rio de Janeiro (UERJ), João Cezar Castro Rocha, autor de Guerra cultural e retórica do ódio - Crônicas de um Brasil pós-político (2021), livro lançado recentemente que apresenta uma análise sobre as estratégias criminosas que a família Bolsonaro e seus seguidores usam na criação de inimigos imaginários e de falsas narrativas para mobilizar suas bases e tirar o foco da ausência sistemática de ações do governo federal diante da gravidade dos problemas enfrentados diariamente pela sociedade brasileira.

"Pois é bem isso: busco a precária síntese, que Drummond pode não ter descoberto, mas soube converter em poesia" (CASTRO ROCHA, 2021, p. 14-15), declara o autor, na apresentação ao livro, confessando que não lhe saem da cabeça os versos do poema "Nosso tempo" ("Visito os fatos, não te encontro / Onde te ocultas, precária síntese"), incluído em A Rosa do Povo, livro publicado em 1945 por Carlos Drummond de Andrade, no qual o poeta confessa sua desconcertante incapacidade de entender os eventos da experiência-limite da Segunda Guerra Mundial e a crescente polarização ideológica que deu origem à Guerra Fria. Castro Rocha destaca como a retórica do ódio do bolsonarismo, em vez de apenas contestar os fatos da realidade, salta da realidade virtual para o mundo real com um discurso criminoso que procura minimizar a pandemia e promover a disseminação da doença, com uma agenda de ações coordenadas que tentam desacreditar e até ridicularizar recomendações científicas como a necessidade do uso de máscaras e isolamento social, fazendo propaganda igualmente criminosa de medicamentos que são comprovadamente inócuos para prevenir a covid-19 e que proporcionam efeitos colaterais da maior gravidade.

O que Castro Rocha define como "retórica do ódio" vem atualizar e problematizar, na conjuntura política brasileira, as reflexões sobre o discurso de poder, sobre biopolítica e sobre biopoder que tiveram pontos inaugurais com as publicações de Barthes e de Foucault. As mesmas reflexões também ganharam outras implicações nas décadas seguintes, embora conservando o mesmo objeto político, retomadas com frequência ou questionadas por outros autores em contextos diversos, com destaque para os ensaios centrados em polêmicas culturais publicados por Susan Sontag para abordar o sofrimento, as imagens do horror, as guerras e as doenças como metáforas das relações históricas e sociais das sociedades e dos indivíduos, em obras como $A$ doença como metáfora (1984), Aids e suas metáforas (1989) e Diante da dor dos outros (2003) - sendo os dois primeiros dedicados ao tema da violência e do poder que emanam das circunstâncias da doença, individual ou coletiva, dos estigmas e da marginalização dos doentes, e o terceiro uma reflexão sobre como as imagens podem 


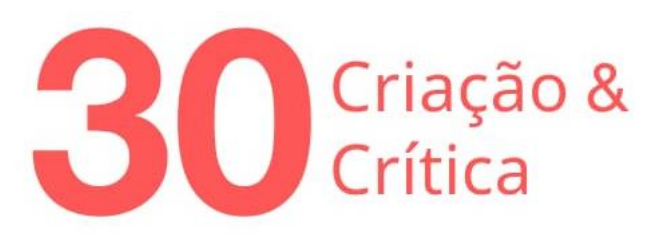

inspirar discórdia, fomentar a violência ou criar apatia, sobre a violência da guerra e sobre a iconografia contemporânea do sofrimento humano como discurso de poder.

Diante da dor dos outros desenvolve uma reflexão sobre o efeito das representações e notícias de violência e de morte em nossas vidas, delineando uma trajetória sobre a evolução dessa iconografia desde as pinturas do espanhol Francisco de Goya (1746-1828), num percurso que alcança as grandes guerras do Oitocentos, as duas guerras mundiais no último século, os campos de concentração nazistas e a Guerra do Vietnã, chegando até as sequências de imagens espetaculares com transmissão ao vivo da destruição do World Trade Center, em 11 de setembro de 2001. Sontag coloca na cena da descrição e análise o nosso modo de recepção desta iconografia, o modo como dela construímos interpretações e sobre como tal fluxo incessante de imagens geradas por câmeras constitui nosso meio ambiente (nas reportagens e nos registros pessoais, em mídias impressas ou digitais, na TV, no cinema) e adquire um imediatismo e uma autoridade muito maiores do que qualquer relato verbal para transmitir os horrores da morte e da violência. A iconografia do sofrimento tem uma longa linhagem na experiência humana, mas o fascínio das imagens produzidas por câmeras revela um certo "consenso tácito" quanto à atração pela imagem roubada.

Queremos que o fotógrafo seja um espião na casa do amor e da morte e que as pessoas fotografadas não estejam conscientes da câmera, estejam "desprevenidas". Nenhuma ideia sofisticada do que a fotografia é ou pode ser jamais enfraquecerá a satisfação proporcionada por uma foto de um acontecimento inesperado, apanhado em pleno curso, por um fotógrafo alerta (SONTAG, 2003, p. 49).

A relevância das experiências sobre os horrores da morte e da violência também fornece os argumentos para Sontag abordar a doença e toda forma de sofrimento que ela envolve e provoca. "A doença é a zona noturna da vida, uma cidadania mais onerosa. Todos que nascem têm dupla cidadania, no reino dos sãos e no reino dos doentes" (1984, p. 4) - são as palavras iniciais para apresentar A doença como metáfora, completando a analogia com a constatação de que todos preferimos usar somente o passaporte do reino dos sãos, porém mais cedo ou mais tarde nos vemos obrigados, ao menos por um período, a nos identificarmos como cidadãos desse outro lugar. Assim como Sontag toma as doenças como referências e metáforas, seja com relação a ocorrências pandêmicas da tuberculose, do câncer ou do HIVIAids no contexto dos séculos XIX e XX, já temos um extenso suporte documental e científico para afirmar que a covid-19 tornou-se uma doença com ocorrência de impacto que marca definitivamente o século XXI. Nas análises de Sontag, apesar de as doenças se apresentarem sempre num caráter de metáfora, há um alerta de que, para realmente enfrentá-las, para a libertação do seu jugo, se faz necessário algum distanciamento das imagens lúgubres com as quais tal reino dos doentes foi pintado por um discurso de poder - que também poderia ser nomeado como biopoder ou biopolítica. 


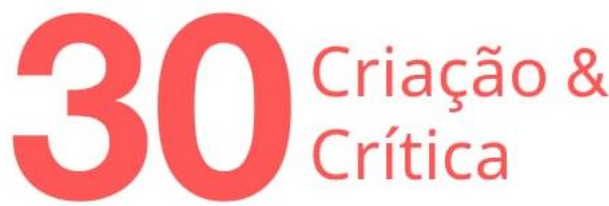

Em analogia às considerações e conclusões de Sontag sobre uma diversidade de eventos e contextos históricos relacionados às doenças e à violência, podemos ressaltar que metáforas são também ferramentas centrais e fundamentais na atualidade de nossas experiências com os processos de subjetivação da pandemia de covid-19, seja no expediente das quarentenas sucessivas, no imperativo de sobrevivência do isolamento social, no uso obrigatório de máscaras, seja na urgência de vacinação contra o vírus invisível e maligno e contra o contágio que ele materializa. Seguindo as reflexões de Sontag, constatamos as formas similares de preconceitos, de racismo e de outras violências, outras pestes, outras epidemias do passado. Assim como houve o estigma social da doença como castigo e como resultado de uma vida leviana de excessos (a exemplo da tuberculose, no século XIX), ou como reflexo somático e enigmático de contenções do prazer (o câncer, no século passado), ou em decorrência da promiscuidade atribuída exclusivamente aos homossexuais como estratégia de marginalização (a Aids, a partir das últimas décadas do século XX), poderíamos traçar os passos, no contexto político brasileiro, de uma equivalência da "retórica do ódio" ou do biopoder no discurso e nos dispositivos pelos quais o bolsonarismo procura conduzir a pandemia com metáforas de caráter bélico.

Não é por acaso que o próprio presidente da República e muitos de seus apoiadores centram esforços na promoção de medicamentos sem nenhuma eficácia comprovada, e em muitos casos letais nas consequências, em resposta à magnitude da pandemia. De forma deliberada, e insistentemente, promovem a desinformação e espalham mentiras criminosas, as famigeradas "fake news", defendendo uma delirante e absurda tese da "imunidade do rebanho" (como se a resistência à covid19 pudesse ocorrer por meio da contaminação de todos) e fazendo propaganda de um inexistente "tratamento precoce" à base de cloroquina e hidroxicloroquina, remédios usuais para tratar pacientes com malária ou artrites reumatoides, ou ivermectina, fármaco recomendado para combater infestações por parasitas como piolhos e lombrigas intestinais. $O$ fato de tais medicamentos terem passado à produção em larga escala pelo Exército brasileiro vem ressaltar o caráter bizarro, bélico e militarizado da metáfora: tomada como "munição" na guerra contra o vírus, as "armas", alardeadas como prevenção e salvação, na verdade apenas resultam em medicação inócua contra a doença e sujeita a provocar efeitos colaterais da maior gravidade, como comprovam fontes credenciadas da comunidade científica internacional e da Organização Mundial da Saúde (OMS) (OMS..., 2021). No contexto da retórica do ódio, o vírus, invisível e mortal, não é combatido e sim promovido, pois sua propagação é incentivada pelo discurso distorcido e enganador.

Em sua forma insólita de embuste autoritário, tal discurso de poder remete ao pressuposto da "língua fascista" na Aula Inaugural de Barthes no Collège de France, apresentada quase uma década depois das revoltas estudantis de maio de 1968, com suas barricadas nas ruas e suas utopias libertárias que começaram em Paris e, rapidamente, se alastraram para outras cidades e outros países, incluindo o Brasil, que naquele momento passava ao período mais violento da repressão instalada pela 


\section{$300_{\text {Críticãa \& }}^{\text {Crià }}$}

ditadura militar. Barthes não foi um militante ativo em maio de $1968^{3}$, e chegou mesmo a ser considerado "reacionário" por alguns grupos de manifestantes, mas ele cita, mais de uma vez, o marco da ruptura daquele momento histórico das revoltas estudantis como contraponto para sua Aula. E reconhece, ainda que entoando um certo ceticismo, o "deslocamento político" que modificou e permanece a modificar a imagem crítica, tanto do sujeito social como do sujeito falante, frente ao discurso de poder, o discurso universal.

A semiologia deslocou-se depois disso, coloriu-se diferentemente, embora conservando o mesmo objeto, político - pois não existe outro. Esse deslocamento fez-se porque a sociedade intelectual mudou, quando mais não fosse pela ruptura de maio de 68 (...). Uma espécie de excitação moral tomou conta dos corpos políticos e, mesmo quando se reivindicava a favor do gozo, era num tom cominatório. Viram-se assim a maior parte das liberações postuladas, as da sociedade, da cultura, da arte, da sexualidade, enunciar-se sob as espécies de um discurso de poder: vangloriavam-se de pôr em evidência o que havia sido esmagado, sem ver o que, assim fazendo, se esmagava alhures (BARTHES, 1978, p. 34-35).

Em seguida, na mesma Aula, há confissões do autor sobre o necessário enfrentamento contra o discurso de poder por meio do "logro consciente" dos signos, seus objetos de predileção nos textos do Imaginário (definidos por ele como "as narrativas, as imagens, os retratos, as expressões, os idioletos, as paixões, as estruturas que jogam ao mesmo tempo com uma aparência de verossimilhança e com uma incerteza de verdade"), um enfrentamento que se torna "concebível graças a certas mutações recentes, que afetam mais a cultura do que a própria sociedade" - e há, também, a ressalva de que o discurso de ruptura de maio de 1968 manifestou, também, uma certa crise do ensino: "os valores antigos não se transmitem mais, não circulam mais, não impressionam mais" (BARTHES, 1978, p. 40-41). Superando o paradoxo de "produzir deciframentos e apresentar resultados", há o argumento de que a luta antagônica entre poder coletivo e contrapoder revolucionário também acontece na linguagem, no contexto que por sua própria natureza é fluido e instável, "nesse ensino que, por seu próprio lugar, nada é chamado a sancionar, senão a fidelidade de seus ouvintes" (BARTHES, 1978, p. 42). Barthes também aponta que a verdadeira raiz do antagonismo político se encontra no seio da própria linguagem, motivo pelo

\footnotetext{
${ }^{3}$ Louis-Jean Calvet destaca que, em meio à agitação geral de maio de 1968, com tantas manifestações múltiplas e desordenada, Barthes se coloca um pouco de lado, sem um mínimo de entusiasmo. "Ele, que sempre estivera do lado, ou ao lado, da vanguarda, não encontra aí nada que justifique, a seu ver, seu apoio, e sua reação parece de desconfiança e reprovação. Esta desconfiança não se reflete na sua obra, salvo três anos depois, numa curta passagem de Sade, Fourier, Loyola. Fourier, diz ele, escolhera o doméstico em vez do político, pois o político reside no oposto do desejo, exceto no caso da neurose de politização. E ilustra assim esta preposição: 'Em maio de 68, propôs-se a um dos grupos que se formaram espontaneamente na Sorbonne que se estudasse a utopia doméstica - pensava-se evidentemente em Fourier; responderam que a expressão era muito rebuscada, logo burguesa'" (CALVET, 1993, p. 188-189).
} 


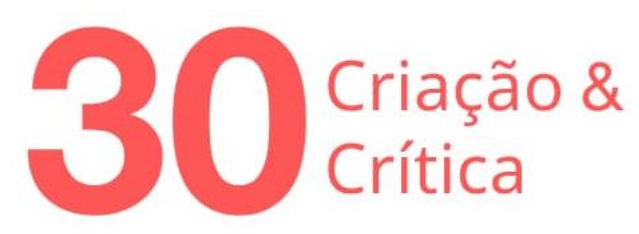

qual, na analogia entre língua e ideologia, ele vai identificar o discurso autoritário e enganador, o embuste que associa o poder incorporado na linguagem ao poder tecnocrático das instâncias políticas da sociedade.

A tese central em Aula, sobre o poder repressivo do discurso ("a língua é simplesmente fascista"), também revela, nas entrelinhas, o antídoto contra esse poder repressivo ao enunciar outras possibilidades de contradição e subversão política, um convite à utopia em sua plena capacidade para acreditar que seja sensato o desejo do impossível. A mesma referência com intenção libertária surge também em outros textos de sua trajetória como professor e escritor - como nos fragmentos confessionais de Roland Barthes por Roland Barthes, publicado em 1975, quando ele alerta que todo fato histórico é inalienável ("a História, a mais segura das ciências humanas") (BARTHES, 1978, p. 44) e que, entre a ideologia (ou a contraideologia) e a estética, pode-se acusar o sujeito de contradição, ou induzir dessa contradição um espanto, como o feiticeiro que consegue fixar o mal da tribo primitiva ou como aqueles antigos eruditos que acrescentavam sabiamente, após uma determinada proposição, o corretivo "incertum" (BARTHES, 2017, p. 121).

Que fazer? Uma solução é possível: a estética. Em Brecht, a crítica ideológica não se faz diretamente (senão, ela teria produzido uma vez mais um discurso repetitivo, tautológico, militante); ela passa por mediações estéticas; a contraideologia se infiltra sob uma ficção, não realista, mas justa. Este é talvez o papel da estética em nossa sociedade: fornecer as regras de um discurso indireto e transitivo (ele pode transformar a linguagem, mas não exibe seu domínio, sua boa consciência (BARTHES, 2017, p. 120).

Por fim, confrontados com a irrealidade cotidiana e permanente de um discurso de poder tão distorcido e enganador, vale concluirmos com Barthes na visualização de alguma esperança sobre a transparência dos "clarões de desejo" de uma utopia tão sonhada e tão continuamente adiada. A utopia, ou antes a "função utópica" da literatura, em seu encontro com a História, já estava nomeada nas reflexões de Aula, de forma alegórica, na Sapientia ${ }^{4}$ que é apresentada como conclusão, e de forma direta, em outras passagens de seu argumento de provocação e sedução, principalmente nas referências às concepções das utopias de linguagem surgidas com Mallarmé na modernidade, quando Barthes afirma:

A utopia, é claro, não preserva do poder: a utopia da língua é recuperada como língua da utopia - que é um gênero como qualquer

\footnotetext{
4 "Há uma idade em que se ensina o que se sabe; mas vem em seguida outra, em que se ensina o que não se sabe: isso se chama pesquisar. Vem talvez agora a idade de uma outra experiência, a de desaprender, de deixar trabalhar o remanejamento imprevisível que o esquecimento impõe à sedimentação dos saberes, das culturas, das crenças que atravessamos. Essa experiência tem, creio eu, um nome ilustre e fora de moda, que ousarei tomar aqui sem complexo, na própria encruzilhada de sua etimologia: Sapientia: nenhum poder, um pouco de saber, um pouco de sabedoria, e o máximo de sabor possível" (BARTHES, 1978, p. 47).
} 


\section{Criação \&}

outro. Pode-se dizer que nenhum dos escritores que partiram de um combate assaz solitário contra o poder da língua, pôde ou pode evitar ser recuperado por ele, quer sob a forma póstuma de uma inscrição na cultura oficial, quer sob a forma presente de uma moda que impõe sua imagem e the prescreve a conformidade com aquilo que dele se espera. Não há outra saída para esse autor senão o deslocamento ou a teimosia - ou os dois ao mesmo tempo (BARTHES, 1978, 25-26).

"A Utopia" também é o título de um texto tão breve como pouco conhecido de Barthes, publicado originalmente em 1974, por intervenção de Umberto Eco, no L'Almanaco Bompiani, da Casa Editrice Bompiani di Milano, Itália, e ainda ausente das edições em francês de suas Obras Completas. Escrito sob encomenda, e incluído na edição brasileira de 2005 de seus textos inéditos sobre política, "A Utopia", no lugar de apenas delimitar uma definição ou estabelecer um verbete de enciclopédia, configura possibilidades poéticas sobre este conceito instável e ambivalente que "arruína o tempo presente, sempre se apoia no que não vai bem no mundo e, ao mesmo tempo, também inventa imagens de felicidade: inventa-as com sua cor, sua precisão, suas cambiâncias, sua absurdez mesmo; tem a mais rara das coragens: a do gozo" (BARTHES, 2005, p. 192).

Na breve abordagem de Barthes, que sempre foi um utopista autêntico, como apontam seus biógrafos, as utopias são "o campo do desejo, diante da política, que é o campo da necessidade"; e elas "não são apenas justificadas, mas também necessárias". Diante da abertura dos projetos sonhados por uma ideia utópica, também caberia a cada um de nós, na condição de intelectuais, escritores, leitores, um questionamento sobre os limites e os deveres da solidariedade e da consciência para desempenharmos papéis de resistência efetiva e de combate à manipulação ideológica, pois somente dessa forma conquistamos oportunidades para dissolver a dominação do discurso de poder e para superar, finalmente, pelo poder do discurso, a distorção das falácias e os mecanismos autoritários das línguas e linguagens, construindo outros mundos possíveis para o bem viver. Com Barthes, encontramos no sistema utópico não uma teoria, e sim um olhar, uma intuição para um limiar político e poético:

Claro que, como sistema inteiro, nenhuma utopia tem a menor chance de aplicação: o falanstério de Fourier e o castelo sadiano são, literalmente, impossíveis; mas são os elementos, as inflexões, os meandros, os recônditos do sistema utópico que retornam ao nosso mundo como clarões do desejo, possibilidades exaltantes: se os captássemos melhor, eles impediriam que a Política se enrijecesse em sistema totalitário, burocrático, moralizador (BARTHES, 2005, p. 192-193). 


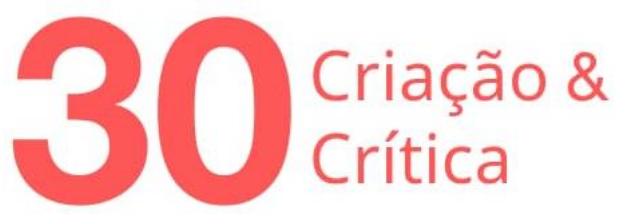

\section{Referências}

A COMPLETE massacre, a horror film: inside Brazil's Covid disaster. The Guardian, 24 Jan. 2021. Disponível em: <https://www.theguardian.com/world/2021/jan/24/brazilcovid-coronavirus-deaths-cases-amazonas-state> Acesso em: 15 abril 2021.

BARTHES, Roland. Roland Barthes por Roland Barthes. Trad. Leyla Perrone-Moisés. São Paulo: Estação Liberdade, 2017.

BARTHES, Roland. Inéditos, vol. 4 : Política. Trad. Ivone C. Benedetti. São Paulo: Martins Fontes, 2005.

BARTHES, Roland. Aula. Aula inaugural da cadeira de Semiologia Literária no Collège de France, pronunciada dia 7 de janeiro de 1977. Trad. Leyla Perrone-Moisés. São Paulo: Editora Cultrix, 1978.

BARTHES, Roland. Mitologias. Trad. Rita Buongermino e Pedro de Souza. São Paulo: Difusão Europeia do Livro, 1972.

BODIN, Jean. Os seis livros da República. Vol. 1. Trad. José Carlos Orsi Morel. São Paulo: Editora Ícone, 2011.

CALVET, Louis-Jean. Roland Barthes: uma biografia. Trad. Maria Ângela Villela da Costa. São Paulo: Siciliano, 1993.

CASTRO ROCHA, João Cezar. Guerra cultural e retórica do ódio - Crônicas de um Brasil pós-político. Goiânia: Editora Caminhos, 2021.

COVID: Bolsonaro tells brazilians to 'stop whining' as deaths spike. $B B C, 5$ March 2021. Disponível em: <https://www.bbc.com/news/world-latin-america-56288548> Acesso em 15 abril 2021.

DIDI-HUBERMAN, Georges. A imagem sobrevivente: história da arte e tempo dos fantasmas segundo Aby Warburg. Trad. Vera Ribeiro. Rio de Janeiro: Contraponto, 2013.

EDITORIAL: The Guardian view Jair Bolsonaro; a danger to Brazil, and the world. The Guardian, 5 Apr. $2021 . \quad$ Disponível em: $<$ https://www.theguardian.com/commentisfree/2021/apr/05/the-guardian-view-on-jairbolsonaro-a-danger-to-brazil-and-the-world> Acesso em: 15 abril 2021.

EM PIOR momento da pandemia, Bolsonaro critica 'mimimi' e diz que brasileiro tem que enfrentar vírus. BBC News Brasil, 4 mar. 2021. Disponível em: $<$ https://www.bbc.com/portuguese/brasil-56287135> Acesso em 15 abril 2021.

ESTUDO atribui fracasso do Brasil na pandemia ao governo federal. Deutsche Welle, 15 abr. 2021. Disponível em: <https://www.dw.com/pt-br/estudo-atribui-fracasso-dobrasil-na-pandemia-ao-governo-federal/a-57219075> Acesso em: 15 abril 2021.

FOUCAULT, Michel. História da sexualidade: A vontade de saber (Vol. 1). Trad. Maria Thereza da Costa Albuquerque e J. A. Guilhon Albuquerque. São Paulo, Edições Graal, 2010. FOUCAULT, Michel. Em defesa da sociedade: Curso dado no Collège de France (1975-1976). Trad. Maria Ermentina Galvão. São Paulo: Martins Fontes, 1999.

INAÇÃO e desinformação do governo Bolsonaro agravam a pandemia no Brasil. El País, 15 abr. 2021. Disponível em: <https://brasil.elpais.com/brasil/2021-0416/inacao-e-desinformacao-do-governo-bolsonaro-agravam-a-pandemia-no-

brasil.html> Acesso em: 15 abril 2021.

LA BOÉTIE, Étienne de. Discurso sobre a servidão voluntária. Trad. Evelyn Tesche. São Paulo: Edipro, 2017.

OMS: Hidroxicloroquina não funciona contra covid-19 e pode causar efeito adverso. CNN Brasil, 2 mar. 2021. Disponível em: $<$ https://www.cnnbrasil.com.br/saude/2021/03/02/oms-cloroquina-nao-funcionacontra-a-covid-19-e-pode-causar-efeitos-adversos > Acesso em: 15 abril 2021. 


\section{$300_{\text {Critica }}^{\text {Criacão \& }}$}

OPINION: Brazil's Bolsonaro failed to stop covid-19. Now he may be targeting democracy. The Washington Post, 2 Apr. 2021. Disponível em: $<$ https://www.washingtonpost.com/opinions/global-opinions/brazils-bolsonaro-failedto-stop-covid-19-now-he-may-be-targeting-democracy/2021/04/02/ab049ae0-930411eb-a74e-1f4cf89fd948 story.html> Acesso em: 15 abril 2021.

PERRONE-MOISES, Leyla. Roland Barthes. São Paulo: Editora Brasiliense, 1983.

PLAYING WITH lives: Brazil's covid vaccine plan is mired in chaos. The New York Times, "Playing with lives: Brazil's covid vaccine plan is mired in chaos", 14 dec. 2020. Disponível em: <https://www.nytimes.com/2020/12/14/world/americas/brazilcoronavirus-vaccine.html Acesso em: 15 abr. 2021.

SONTAG, Susan. Diante da dor dos outros. Trad. Rubens Figueiredo. São Paulo: Companhia das Letras, 2003.

SONTAG, Susan. AIDS e suas metáforas. Trad. Paulo Henriques Britto. São Paulo: Companhia das Letras, 1989.

SONTAG, Susan. A doença como metáfora. Trad. Márcio Ramalho. Rio de Janeiro: Graal, 1984.

Recebido em: 01/05/2021Aceito em: 29/07/2021

Referência eletrônica: ORLANDO, José Antônio. CASA NOVA, Vera. Uma retórica do poder. Criação \& Crítica, n. 30, p., set. 2021. Disponível em: <http://revistas.usp.br/criacaoecritica>. Acesso em: dd mmm. aaaa. 